\title{
PARTICIPAÇÃO POLÍTICA E A PERSPECTIVA FILOSÓFICA DA POLÍTICA
}

Neivor Schuck ${ }^{1}$

Resumo: Reflete sobre a construção de um modelo de democracia fundado na participação política enfatizando a necessidade da educação política do cidadão. A âncora desta forma de organização de poder remete à concepção de democracia participativa. Para analisarmos estes aspectos na realidade brasileira, utilizamos o referencial de três filósofos: Rousseau, que acredita na possibilidade da educação construir um homem com responsabilidade e engajado nas discussões acerca de sua vida prática; Alexis de Tocqueville, que ao escrever a democracia na América, pretende mostrar que é possível viver em um regime democrático que valorize os diferentes de acordo com suas demandas; e Montesquieu, que ao dividir o poder em três partes, acredita no bom funcionamento de um regime democrático fundado no esclarecimento dos cidadãos.

Palavras chave: educação política, poder, democracia, Tocqueville, Montesquieu, Rousseau.

Abstract: Study about the construction of a democracy model based on political participation emphasized the need for political education of citizens. The anchor of this form of organization of power refers to the design of participatory democracy. Three philosophers are considered by thinking about these issues in the Brazilian reality: Rousseau believed in the possibility of education to build a man with responsibility and engaged in discussions about their practical life, Alexis de Tocqueville when he wrote that democracy in America is intended to show that possible to live in a democracy that values differ according to their demands, and Montesquieu that by dividing power into three parts believe the proper functioning of a democratic regime based on the clarification of the citizens.

\footnotetext{
${ }^{1}$ Professor do GESP/FILOSOFIA, Mestre em Ciências da Religião pela Pontifícia Universidade Católica de São Paulo. (neivorschuck@yahoo.com.br)
} 
Keywords: education policy, power, democracy, Tocqueville, Montesquieu, Rousseau.

A vida em sociedade requer expressiva participação dos cidadãos para que possamos chamá-la de democrática. A ideia não é nova e faz parte de grande parte das reflexões filosóficas de autores que atravessaram os séculos com seus pensamentos. O intuito desse trabalho é apresentar a contribuição de alguns filósofos quanto à necessidade de conscientização no exercício da política por parte dos cidadãos.

A sociedade moderna desenvolveu um sistema eleitoral fundado na representatividade que deveria se apoiar no esclarecimento dos indivíduos que compõem o sistema eleitoral. Segundo Rousseau ${ }^{2}(1973$, p.7) a educação depende da construção de um sentido para a aprendizagem. Para o Filosofo, a participação dos indivíduos nos debates depende da construção da consciência de cidadão. A ideia apresentada na obra Emilio representa a necessidade do ser humano de ser acompanhado no processo de aprendizagem e de tomada de consciência.

Para o filosofo o homem nasce bom e no contrato social existe uma construção de desigualdade. Visto que por natureza o homem é bom. E igual. É no momento do estabelecimento do contrato social que o potencial argumentativo do cidadão se manifesta e a propriedade privada se destaca como diferencial. Isso aplicado à filosofia política, aponta a necessidade de uma educação política fundada na capacidade do cidadão de reivindicar e propor suas demandas. Contudo, a necessidade de esclarecimento e educação são condições fundamentais para que o povo saiba o que é o bem, isso porque: "o povo, por ele próprio, quer sempre o bem, mas, por ele próprio, nem sempre o conhece" (ROUSSEAU, 1973, p.8). Por não saber ele mesmo o que é o bem, o povo precisa de educação política para saber como reivindicar as suas demandas.

As demandas propostas pelo cidadão precisam ser claras para que possa manifestar o principio básico da democracia, que é a possibilidade de o cidadão ter aspirações diferentes. Partindo do pressuposto empírico de Rousseau, (1973, p. 9) de que "o primeiro raciocínio do homem é de natureza sensitiva, nossos primeiros mestres de filosofia são os nossos pés, as nossas mãos, os nossos olhos", podemos considerar que o meio ou a realidade concreta do cidadão dependem da maneira como ele se relaciona com suas realidades sensitivas. Este

\footnotetext{
${ }^{2}$ Jean-Jacques Rousseau, (28 de Junho de 1712, Genebra - 2 de Julho de 1778, Ermenonville, perto de
} Paris). Escritor e filósofo suíço. 
detalhe distingue seres livres de não livres, pois, segundo o filósofo, a liberdade depende da educação e do modo de conceber a realidade e a sociedade.

Seguindo a esteira da liberdade proposta por Rousseau, o francês Alexis de Tocqueville (1987) defende a ideia de que a democracia existe nos EUA porque os cidadãos personificam a noção de liberdade ao propor suas demandas por meio de argumentos. Deste modo, na América, existem condições de igualdade para os cidadãos, todos tendo condições iguais para realizar suas potencialidades, tese defendida com veemência pelo autor.

A proposta de Montesquieu (1973), por sua vez, é estruturar as ações do Estado em três poderes: o Executivo, o Legislativo e o Judiciário. Isso daria condições iguais para todos os cidadãos, visto que o poder não está na mão de um só. Ao Poder Legislativo é reservado o direito de fazer ou modificar leis, estabelecer como se deverá utilizar a força da comunidade no sentido de preservação dela própria e de seus membros. $\mathrm{O}$ autor considera perigoso que o poder se concentre nas mãos de um só, sendo para tanto, necessário que os responsáveis pela construção e alteração das leis não sejam os mesmos que as ponham em prática, pois o ser humano possui a tentação de executá-las em seu beneficio. Desse modo, se forem os mesmos sujeitos que legislam e executam, acontecerá que, em alguns casos, eles poderão se eximir da lei. Isso implica em movimento duplo de corrupção, pois podem moldar as leis quando as fazem e quando as executam. Quando o Poder Legislativo acumula o poder de executar, acaba infringindo a sua incumbência, que é a de fazer as leis de acordo com os anseios da população, facilitando sua execução.

A composição do Poder Legislativo deixa clara a sua função, porque se compõe de legisladores eleitos por voto direto, com a incumbência de representar o povo e de fazer as leis que devem reger essa sociedade. Portanto, os legisladores também são submissos a essas leis. Com efeito, Montesquieu (1973) introduz uma nova concepção de lei, ou seja, pode-se mudá-la caso não esteja respondendo adequadamente aos anseios das pessoas. Isso implica no rompimento da concepção tradicional de não permitir a discussão da lei mesmo que ela fosse injusta, ou inadequada. Representa uma substituição do princípio da lei enquanto controle divino imutável e inquestionável, pela democracia (ou o que se entendia por ela), ou seja, a essência da sociedade moderna. Ao Legislativo é designada a responsabilidade de construir leis e discutir novas propostas. Assim, cabe a ele defender a integridade dos indivíduos através da formulação de leis, ou seja,

Já que num estado livre todo homem que supõe ter uma alma livre deve governar a si próprio, é necessário que o povo no seu conjunto, possua o poder legislativo. Mas como isso é impossível nos grandes Estados, e sendo sujeito a muitos inconvenientes nos pequenos, é preciso que o povo, através de seus representantes, faça tudo o que não pode fazer por si mesmo. (MONTESQUIEU, 1973, p. 158). 
Desta forma, ao Poder Legislativo é conferido o potencial de formular as leis que regem o Estado. Ou seja, apresentar projetos por iniciativa própria ou por iniciativa da sociedade. Assim, a incumbência de legislar consiste na elaboração de projetos de lei, na tentativa de regulamentar por intermédio da representatividade que lhe é conferida pela população, os anseios da comunidade democrática. Desta maneira, os parlamentares compõem o Poder Legislativo e respondem pela formulação das regras que regem a sociedade democrática.

O Poder Legislativo, no entender de Montesquieu, não pode sofrer nenhuma interferência em suas deliberações oriundas dos outros dois poderes que compõem o Estado democrático de direito (Executivo e Judiciário), isso porque deve ser levado em conta o principio do equilíbrio na distribuição dos poderes. Ao Poder Executivo cabe "apenas" a função de executar as disposições legais e atuar, quando necessário, por força de decretos: fazer a paz e a guerra, manter relações diplomáticas e receber delegações.

Segundo Montesquieu (1973), o Poder Executivo é responsável pela execução das normas que regem a administração pública. Portanto, cabe ao Executivo colocar em prática as resoluções do Legislativo. Por isso, não é função do Poder Executivo formular leis, porque esta atribuição é exclusiva do Legislativo. Para Montesquieu (1973, p. 157), "tudo estaria perdido se no mesmo homem ou no mesmo corpo dos principais, ou dos nobres, ou do povo exercesse esses três poderes: o de fazer as leis, o de executar as resoluções públicas o de julgar os crimes ou as divergências dos indivíduos”.

Isso implica na autonomia de funcionamento do Poder Executivo, e que este não pode interferir de maneira direta no funcionamento do Legislativo e do Judiciário, o que poderia resultar em tirania, ou seja, em abuso de poder. A preocupação latente de Montesquieu se refere ao fato de o Executivo possuir um excesso de poder, tornando-se totalmente tirânico. Por isso é necessário que o poder esteja na mão de mais de um órgão, porque, se não for desta forma, pode-se construir um regime político autocrático.

Assim, define-se o papel do Executivo e do Legislativo, porque, de acordo com Montesquieu, "o poder Executivo, como dissemos, deve participar da legislação com o direito de veto, sem o que seria despojado de suas prerrogativas. Mas, se o poder legislativo participar da execução, o poder executivo estará igualmente perdido." (MONTESQUIEU, 1973, p. 161).

Isso implica no estabelecimento de um equilíbrio, porque o Executivo possui o direito de vetar matérias de caráter coercitivo, e por sua vez, o poder Legislativo deve buscar um entendimento, para que evite um possível veto causado pela distorção na formulação da lei. Se o Executivo não pudesse vetar o que considera ofensivo, estaria subordinado ao Legislativo, fato que o anularia. 
Além disso, o Poder Judiciário possui a função de julgar os que transgridem as leis e os decretos dos outros dois poderes. Assim, o Judiciário possui a incumbência de fiscalizar o funcionamento dos outros poderes (Legislativo e Executivo), bem como o seu modo de estruturação. Composto por magistrados, representantes da esfera jurídica e advogados, ocupase do cuidado e do zelo dos direitos dos cidadãos, ou seja, defende as prerrogativas constitucionais.

Conforme define Montesquieu (1973), o Judiciário é responsável pelo controle, em tese, do funcionamento do Estado nas esferas Legislativa e Executiva e de seu funcionamento administrativo, ou seja, fiscalizar. Com efeito,

\footnotetext{
Não haverá também liberdade se o poder de julgar não estiver separado do poder legislativo e do executivo. Se estivesse ligado ao legislativo, o poder sobre a vida e a morte dos cidadãos seria arbitrário, pois o juiz seria legislador. Se estivesse ligado ao poder executivo, o juiz poderia ter a força de um opressor (MONTESQUIEU, 1973, p.157).
}

O funcionamento equilibrado dos poderes depende, essencialmente, de sua estruturação, embora necessite do material humano para funcionar. Se não existir um sistema eficiente de controle, torna-se impossível a aplicação da lei de maneira equitativa.

Embora o Judiciário possua um cunho técnico, ele se ocupa da interpretação e da significação da legislação, ou seja, é responsável pela averiguação dos casos em sua singularidade e na aplicação coerente da lei.

Tendo em vista a valoração da liberdade, Montesquieu (apud DALLARI, 2003, p. 215) defende a divisão de funções do Estado, ou seja, "a teoria da separação dos poderes, que através de Montesquieu se incorporou ao constitucionalismo, foi concebida para assegurar a liberdade dos indivíduos".

Portanto, embora o Estado seja uno e indifusível, é necessária a distribuição das atribuições, evitando o cerceamento da liberdade dos indivíduos. Porque, de acordo com Montesquieu, "quando na mesma pessoa ou no mesmo corpo de magistratura o poder legislativo está reunido ao poder executivo, não há liberdade, pois se pode esperar que esse monarca ou senado façam leis tirânicas para executá-las tiranicamente" (MONTESQUIEU, 1973, p. 157).

Vimos, até aqui, que o Estado, segundo Montesquieu (1973, p. 156), é composto por três poderes que devem garantir a integridade da democracia e o respeito às instituições:

Assim, há em cada estado três espécies de poderes: o poder legislativo, o poder executivo das coisas que dependem do direito das gentes e o executivo das que dependem do direito civil. Pelo primeiro, o príncipe ou magistrado faz leis por certo tempo ou para sempre e corrige ou ab-roga as que estão feitas. Pelo segundo, faz a paz ou a guerra envia ou recebe embaixadas, 
estabelece a segurança, previne as invasões. Pelo terceiro, pune os crimes ou julga as querelas dos indivíduos. Chamemos este último de poder de julgar, e o segundo simplesmente de poder executivo do Estado.

A estruturação do Estado obedece a esses três princípios fundamentais, para que haja uma concatenação coerente das ações, do planejamento e da fiscalização.

Em sua obra, o filósofo demonstra que a democracia é marcada, sobretudo, pela capacidade da sociedade construir as leis sob as quais deseja viver. Neste sentido, suas ideias se aproximam dos princípios de Rousseau acerca da democracia.

Mas Montesquieu é claro ao afirmar que aos homens não é possível participar ativamente na construção legal. Resta-lhes a escolha dos representantes legisladores. "Todos os cidadãos nos diversos distritos, devem ter direito a dar seu voto para escolher o representante" (MONTESQUIEU, 1973, p. 158). Tal voto diz respeito à constituição do corpo legislativo uma vez que

O corpo representante também não deve ser escolhido para tomar qualquer resolução ativa, coisa que não executaria bem, mas, sim, para fazer leis ou para ver se as que fez são bem executadas, coisa que pode realizar muito bem, e que ninguém pode realizar melhor do que ele.(MONTESQUIEU, 1973, p. 159).

Segundo Montesquieu, o Estado possui uma base democrática fundada no conceito de divisão dos poderes e de equilíbrio entre eles. Assim, ao contrário de Hobbes (2008), que defendia um Estado absoluto, sobretudo na questão individual, Montesquieu introduz a separação entre os poderes para que haja uma relação harmoniosa entre as diferentes partes do Estado democrático. Esta separação dos poderes implica no enfraquecimento do absolutismo, assim o Estado passa a assumir uma postura liberal, o que significa a não interferência no funcionamento do mercado. Portanto, não pode interferir na vida econômica para obter lucro. Deve apenas regular o mercado e garantir a segurança.

Embora os indícios da separação dos poderes estejam presentes em Aristóteles (1991, 1995), Maquiavel, Locke (1991) e outros (MALDONADO, 2003), somente com Montesquieu assume um caráter constitucional, porque se introduz o conceito de autonomia. Portanto, o conceito apresentado por Montesquieu aumenta a eficiência administrativa porque descentraliza a administração. De acordo com Dallari (2003, p. 218):

Finalmente, com Montesquieu, a teoria da separação dos poderes já é concebida como um sistema em que se conjugam um legislativo, um executivo e um judiciário harmônicos e independentes entre si, tomando, praticamente, a configuração que iria aparecer na maioria das constituições.

A principal diferença em relação às ideias de Locke reside no fato de o pensamento do Filósofo Inglês dividir o poder em três esferas, sem considerar, especificamente, o Judiciário. 
De acordo com seus argumentos, o Estado se divide nos poderes Legislativo, Executivo e Federativo, este último que discute questões internacionais.

Por isso, a separação dos poderes defendida por Montesquieu serviu de base para os países democráticos, devido ao caráter harmônico e de independência de cada um dos poderes, além da definição especifica do poder autônomo de julgar, que em Locke (1991) aparece no rol de atribuições do Executivo. Com efeito, a estruturação nestes moldes permite a discussão e a reelaboração das leis, até então, era impossível, já que o soberano governava e ninguém tinha poder de questioná-lo.

A proposta do autor implica no cumprimento rigoroso das disposições e prerrogativas constitucionais que garantam a conservação do Estado democrático de direito. Isto significa que só existe liberdade dentro da lei e do Estado democrático, ou seja, uma sociedade representada e organizada sob um governo escolhido por ela, como já demonstramos. Portanto, para Montesquieu (1973, p. 156), "uma constituição pode ser de tal modo, que ninguém será constrangido a fazer coisas que a lei não obriga e a não fazer as que a lei permite". Desta maneira, o cidadão deve cumprir as determinações implicadas na lei para manter a sua liberdade.

O conceito de democracia em Montesquieu relaciona-se diretamente com o de liberdade, pois o constitucionalismo pressupõe que o indivíduo é livre para fazer tudo o que as leis permitem 3. Segundo o autor deve se ter em mente que "a liberdade é o direito de fazer tudo o que as leis permitem"; (MONTESQUIEU, 1973, p. 156) porque "se um cidadão pudesse fazer tudo o que elas (leis) proíbem, não teria mais liberdade, porque os outros também teriam tal poder". (MONTESQUIEU, 1973, p. 156).

A despeito da criação de um Estado democrático, baseado na divisão dos poderes, Montesquieu se afasta do pensamento de Locke porque enquanto esse defende o liberalismo de mercado e um poder sem representatividade e fundamentado apenas no parlamento, ou seja, o poder da ultima palavra ${ }^{4}$ Montesquieu argumenta em prol da divisão e do equilíbrio dos poderes.

Parece plausível destacar que a busca por estabilidade sempre esteve presente nos diversos regimes políticos, ou seja, os governantes tentaram manter a ordem de diversas formas: usando a força, impondo decretos etc. Na tentativa de diminuir este problema, Montesquieu propõe a divisão dos poderes.

Tanto a teoria da divisão dos poderes quanto à proposta da democracia esclarecida defendida por Tocqueville, que permite igualdade teórica para todos os cidadãos, propõem uma

\footnotetext{
${ }^{3}$ A liberdade de acordo com os limites da lei pode pressupor ausência de liberdade ou "liberdade entre limites", para essa discussão ver Dantas (2005), como o autor discute este conceito em Hobbes.

${ }^{4}$ No pensamento de Locke o poder está concentrado nas mãos do primeiro ministro e a nobreza contribui com grande parte dos deputados. Mesmo que exista um bicameralismo, não existe uma representatividade direta dos cidadãos no parlamento. (Segundo Tratado do Governo Civil).
} 
república representativa que se apoia na ideia de que os cidadãos livres são capazes de se organizar e propor suas demandas. Deste modo, a construção de uma identidade nacional depende do nível de esclarecimento de um povo, de sua forma de encarar a realidade concreta e propor suas demandas através de argumentos, e nunca pela força.

\section{Referências}

ARISTÓTELES. Ética a Nicômaco. São Paulo: Nova Cultural, 1991.

ARISTÓTELES. Política. Bauru: Edipro, 1995.

BRASIL. Constituição da República Federativa do Brasil. Brasília, DF: Senado 1988.

DALLARI, D. A. Elementos de teoria geral de Estado. 24. ed. São Paulo: Saraiva, 2003.

HOBBES, T. Leviatã. São Paulo: Icone. 2008.

LOCKE, J. Ensaio Acerca do Entendimento Humano; Segundo Tratado Sobre o Governo. 5. ed. São Paulo: Nova Cultural, 1991.

MALDONADO, M. Separação dos Poderes e mecanismos de freios e contrapesos: desenvolvimento no Estado brasileiro. Revista Jurídica "9 de julho", São Paulo, v. 2, n. 2. p. 235-256, 2003.

MONTESQUIEU. Do espírito das leis. São Paulo: Abril Cultural, 1973.

TOCQUEVILLE, Alexis de. A democracia na América. 3. ed. São Paulo: Itália, 1987.

Artigo recebido em: 13/09/2011

Artigo aceito para publicação em: 24/10/2011 